\title{
Urban Sprawl as a Risk Factor in Motor Vehicle Occupant and Pedestrian Fatalities
}

| Reid Ewing, PhD, Richard A. Schieber, MD, MPH, and Charles V. Zegeer, MS

Motor vehicle traffic deaths remain the leading cause of death among Americans aged between 1 and 34 years. In 2001, traffic crashes accounted for about 38000 deaths, of which an estimated 4700 were pedestrians. ${ }^{1}$ Although only about $5 \%$ of all trips are made on foot, ${ }^{2}$ pedestrian fatalities make up about $12 \%$ of all traffic deaths, making walking one of the most dangerous modes of travel. $^{3}$

Urban sprawl is suspected to be a major contributing cause of automobile and pedestrian traffic fatalities, but data supporting this suspicion are sparse. ${ }^{3-6}$ Although "sprawl" has been variously defined, we consider the term to apply to any environment characterized by the following: a population widely dispersed in low-density residential development; rigid separation of homes, shops, and workplaces; a lack of distinct, thriving activity centers, such as strong downtowns or suburban town centers; and a network of roads marked by very large block size and poor access from one place to another. ${ }^{7}$ One research group recently found that the most dangerous places to walk were sprawling metropolitan areas in the South and West, especially Orlando, Tampa-St Petersburg-Clearwater, West Palm Beach-Boca Raton, Memphis, Miami-Ft Lauderdale, Jacksonville, Houston, PhoenixMesa, Dallas-Ft Worth, and Nashville. ${ }^{3}$ However, because sprawl was not measured explicitly, the possible association between sprawl and traffic fatalities could not be tested.

Previous studies modeled pedestrian crashes along roadway segments. The number of pedestrian-motor vehicle collisions has been shown to vary directly with pedestrian volume and traffic volume. ${ }^{4,5}$ Suburban and outlying intersections have been significantly overrepresented in pedestrian crashes compared with more urban areas, after control for exposure and other location factors. The hypothesis that suburban roadways are particu-

Objectives. We sought to determine the association between urban sprawl and traffic fatalities.

Methods. We created a sprawl index by applying principal components analysis to data for 448 US counties in the largest 101 metropolitan areas. Regression analysis was used to determine associations between the index and traffic fatalities.

Results. For every $1 \%$ increase in the index (i.e., more compact, less sprawl), all-mode traffic fatality rates fell by $1.49 \%(P<.001)$ and pedestrian fatality rates fell by $1.47 \%$ to $3.56 \%$, after adjustment for pedestrian exposure $(P<.001)$.

Conclusions. Urban sprawl was directly related to traffic fatalities and pedestrian fatalities. Subsequent studies should investigate relationships at a finer geographic scale and should strive to improve on the measure of exposure used to adjust pedestrian fatality rates. (Am J Public Health. 2003;93:1541-1545)

larly dangerous for pedestrians deserves to be tested at the macrolevel for a greater diversity of settings.

We recently measured urban sprawl at the level of the metropolitan area, using the 4 sprawl indicators just described to create a sprawl index. ${ }^{8}$ In this study, the sprawl index was strongly associated with the overall traffic fatality rate, as well as with an array of transportation outcomes (e.g., percentage of residents walking or taking transit to work, average vehicle ownership, vehicle miles traveled per capita) and environmental outcomes (e.g., ground-level ozone levels).

In another recent study, we measured urban sprawl at the county level, using fewer variables than were available at the metropolitan level, and related county sprawl to leisure time physical activity, obesity, and certain chronic health problems associated with physical inactivity and obesity. ${ }^{9}$ After we controlled for individual covariates such as gender, age, race/ethnicity, and education, sprawl proved to be significantly related to leisure time walking, obesity, and hypertension but not to overall physical activity, diabetes, or coronary heart disease.

The current study is a cross between the earlier 2 studies. It related sprawl to traffic fatalities as in the first study but also measured sprawl at the county level as in the second study. Large metropolitan areas mostly in- clude several counties, each with differing development patterns. The finer geographic scale in this study might be expected to increase the explanatory power of resulting sprawl measures relative to the earlier metropolitan-level traffic fatality study.

\section{METHODS}

The sample in this study consisted of 448 metropolitan counties or statistically equivalent entities (e.g., independent towns and cities) according to the 1990 census, the latest year for which metropolitan boundaries were defined at the time our study began. These counties made up the 101 most populous metropolitan statistical areas, consolidated metropolitan statistical areas, and New England county metropolitan areas in the United States. Nonmetropolitan counties and metropolitan counties in smaller metropolitan areas were excluded from the sample. More than 183 million Americans-nearly two thirds of the United States population-lived in these 448 counties in $2000 .^{10}$

Although sprawl has the 4 characteristics noted earlier, only 2 have been measured at the county level-low residential density and poor street accessibility. A county-based sprawl index was constructed as the main independent variable. It was composed of $6 \mathrm{ob}-$ served variables: 4 related to residential den- 
sity and 2 related to street accessibility from 1 place to another. We used US Census data to derive 3 population density measures for each county: (1) gross population density (persons per square mile); (2) percentage of the county population living at low suburban densities-specifically, densities between 101 and 1499 persons per square mile, corresponding to less than 1 housing unit per acre; and (3) percentage of the county population living at moderate to high urban densitiesspecifically, more than 12500 persons per square mile, corresponding to about 8 housing units per acre, the lower limit of density needed to support mass transit. ${ }^{11}$ In deriving these county population density measures, we excluded census tracts with fewer than 100 inhabitants per square mile (corresponding to rural areas, desert tracts, and other undeveloped lands) located within the county, because we were interested in studying sprawl in developed areas. A fourth, independent net-density variable was derived from estimated urban land area for each county from the Natural Resources Inventory of the US Department of Agriculture. ${ }^{12}$

Data reflecting street accessibility for each county were obtained from US Census data, based on information concerning block size. ${ }^{13}$ A census block is defined as a statistical area bounded on all sides by streets, roads, streams, railroad tracks, or geopolitical boundary lines, in most cases. ${ }^{14} \mathrm{~A}$ traditional urban neighborhood is composed of intersecting roads that create a boundary around a block or neighborhood. These roads form a grid, with houses built on the 4 sides of the block, facing these roads. ${ }^{15}$ Therefore, the length of each side of that block, and the block size, is relatively small. By contrast, a contemporary suburban neighborhood does not make connections between adjacent cul-de-sacs or loop roads. Instead, local streets connect with the road at the subdivision entrance, which is on 1 side of the block boundary. Thus, the length of a side of a block is quite large, and the block itself often encloses multiple subdivisions to form a superblock extending a halfmile or more on each side. Large block sizes translate to a relative paucity of street connections and alternate routes. For each county, we calculated, first, average block size and second, percentage of blocks with areas less than 0.01 square mile, the size of a typical traditional urban block bounded by sides just over 500 feet in length. Tracts with blocks larger than 1 square mile were excluded from these calculations, because these were likely to be in rural or other undeveloped areas.

We used principal components analysis (SPSS Release 11.01; SPSS Inc, Chicago, Ill) to extract the single component (factor) that best represented the degree of sprawl, as indicated by its capture of the largest amount of common variance of these 6 variables. Because this component captured the majority of the combined variance of these variables, no subsequent components were considered.

To derive a county sprawl index, we transformed the principal component, which had a mean of 0 and a standard deviation of 1 , to a scale with a mean of 100 and a standard deviation of 25 . This transformation produced a more familiar metric (like an IQ scale) and ensured that all values would be positive, thereby enhancing our ability to test nonlinear relationships.

We analyzed the relationship between sprawl and each of 3 dependent variables: the all-mode, county-level traffic fatality rate and 2 county-level traffic fatality rates specific to pedestrians. The all-mode fatality rate included fatal crashes involving private motor vehicles, buses, trains, taxis, bicycles, and pedestrians. We restricted the analysis to traffic fatalities rather than injuries (which greatly outnumber fatalities), because high-quality data at a county level were available only for fatalities. Traffic fatality rates per 100000 population were computed by dividing frequency counts for 2000 obtained from the Fatality Analysis Reporting System ${ }^{16}$ by population counts obtained from the 2000 US Census. $^{10}$

Using these archival data, we conducted an ecological study of the relationship between traffic fatality rates and the sprawl index, using the county as the unit of analysis. Because preliminary analysis indicated that the traffic fatality rate was a nonlinear function of the sprawl index (data not shown), a log-log transformation was performed to yield a more linear relationship between these variables. This involved computing the natural logarithms of all variables in the equation. As an added advantage of this transformation, the resulting regression coefficients could be interpreted as elasticities-that is, as percentage changes in a dependent variable that accompany a $1 \%$ change in independent variables. Elasticities are a common way of summarizing relationships in urban planning literature. Estimated with a log-log regression, elasticities can be assumed to be constant for the range of values in the dataset. We controlled for 3 covariates that could potentially confound the relationship between the sprawl index and traffic fatality rate (average household size, percentage of the population of working age, and per capita income) with data obtained from the 2000 US Census.

We next investigated the relationship between the sprawl index and pedestrian fatalities, using pedestrian fatality counts from the Fatality Analysis Reporting System. Because pedestrian fatality rates depend on the amount of walking, ${ }^{17-20}$ we adjusted for such exposure, using the only 2 measures of pedestrian activity found in a national archival dataset that included county-level information. ${ }^{21}$ These 2 measures were the proportion of all work trips taken on foot and the proportion of work trips taken by public transportation, which generally entails walking to and from a public transit stop. The former measure of pedestrian activity was used to adjust the pedestrian fatality count for 1 type of exposure. The sum of the former and the latter measures was used to adjust the pedestrian fatality count for another type of exposure. Such adjustments are important, because more compact land use patterns would be expected to generate more trips by pedestrians (greater modal share) and therefore greater exposure to hazard.

A log-log transformation was again performed to obtain a more linear relationship between fatality rates and the sprawl index. Because 96 (21\%) of the counties had no pedestrian fatalities in 2000, 2 analyses were conducted. First, counties with no pedestrian fatalities were dropped from the sample, the logarithm of 0 being undefined. Most excluded counties were small, either suburban or exurban, with little pedestrian activity. Second, all counties were included, but 1 fatality was added to the pedestrian fatality count for each county. Accounting for counties with 0 fatalities should minimize a bias toward the 
TABLE 1-Variable Loadings on Spraw Index for Study Counties

\begin{tabular}{lc}
\hline \multicolumn{1}{c}{ Variable } & Loading \\
\hline Census gross density & 0.846 \\
Suburban density $\left(<1500\right.$ persons $/ \mathrm{mi}^{2}$ ) & -0.698 \\
Urban density $\left(>12500\right.$ persons $\left./ \mathrm{mi}^{2}\right)$ & 0.846 \\
Natural Resources Inventory net density & 0.849 \\
Average block size & -0.698 \\
Proportion of blocks $<0.01 \mathrm{mi}^{2}$ & 0.821 \\
Eigenvalue & 3.8 \\
Percentage of variance explained & $63.4 \%$
\end{tabular}

finding that sprawling counties are more dangerous for pedestrians.

We also controlled for the 3 covariates mentioned in the Methods (average household size, percentage of the population of working age, and per capita income). Significance was assumed to exist at $P<.05$.

\section{RESULTS}

In the principal components analysis, each of the 6 observed variables proved to be strongly related to the theoretical construct of urban sprawl (Table 1). The first principal component was positively related to gross population density, net population density, percentage of the county population living at moderate to high urban density, and percentage of small blocks. It was negatively related to percentage of the population living at low suburban density and average block size. Hence, higher values corresponded to a lesser degree of sprawl, and lower values to a greater degree of sprawl.

The absolute value of each loading-that is, the correlation between each of the 6 observed variables and the principal component-exceeded 0.6. The principal component accounted for $63.4 \%$ of the total variance among the 6 component variables.

We ranked the US counties in the sample by their sprawl index. Table 2 indicates which counties had the highest and lowest sprawl index values. Figure 1 shows a scattergram of the natural logarithms of the all-mode traffic fatality rate versus the sprawl index for all 448 counties. The most compact counties (i.e., those with highest population density and street accessibility and, therefore, the

TABLE 2-US Counties With Highest and Lowest Sprawl Index Values

\begin{tabular}{|c|c|c|c|c|}
\hline & County & Metropolitan Area & Sprawl Index & $\begin{array}{c}\text { All-Mode Traffic } \\
\text { Fatality Rate } \\
\text { (per 100000) }\end{array}$ \\
\hline 1 & New York County, NY & New York & 352.07 & 4.42 \\
\hline 2 & Kings County, NY & New York & 263.65 & 4.46 \\
\hline 3 & Bronx County, NY & New York & 250.72 & 4.20 \\
\hline 4 & Queens County, NY & New York & 218.90 & 4.58 \\
\hline 5 & San Francisco County, Calif & San Francisco & 209.27 & 6.31 \\
\hline 6 & Hudson County, NJ & Jersey City & 190.06 & 5.91 \\
\hline 7 & Philadelphia County, $\mathrm{Pa}$ & Philadelphia & 187.78 & 8.04 \\
\hline 8 & Suffolk County, Mass & Boston-Lawrence-Salem & 179.37 & 4.49 \\
\hline 9 & Richmond County, NY & New York & 162.89 & 5.63 \\
\hline 10 & Baltimore City, Md & Baltimore & 162.76 & 7.68 \\
\hline 439 & Stokes County, NC & Greensboro-Winston-Salem-High Point & 71.26 & 15.66 \\
\hline 440 & Miami County, Kans & Kansas City & 71.03 & 38.80 \\
\hline 441 & Davie County, NC & Greensboro-Winston-Salem-High Point & 70.99 & 25.84 \\
\hline 442 & Isanti County, Minn & Minneapolis-St Paul & 70.12 & 12.78 \\
\hline 443 & Walton County, Ga & Atlanta & 69.61 & 19.77 \\
\hline 444 & Yadkin County, NC & Greensboro-Winston-Salem-High Point & 69.17 & 38.52 \\
\hline 445 & Goochland County, Va & Richmond-Petersburg & 67.59 & 35.58 \\
\hline 446 & Fulton County, Ohio & Toledo & 66.83 & 38.02 \\
\hline 447 & Clinton County, Mich & Lansing-East Lansing & 66.63 & 16.99 \\
\hline 448 & Geauga County, Ohio & Cleveland & 63.12 & 20.90 \\
\hline
\end{tabular}

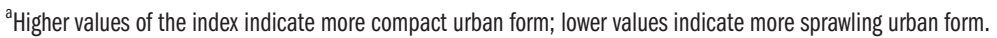

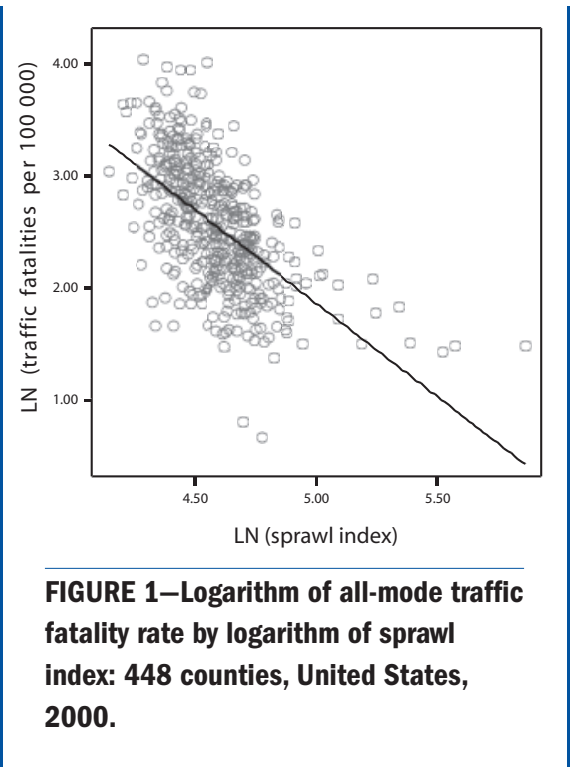

highest index value) were located in the central parts of the nation's oldest and largest metropolitan areas. The least compact counties (most sprawling, lowest index value) were located in outlying parts of smaller metropoli- $\tan$ areas in the Southeast and Midwest. Counties with midrange values on the sprawl index were located in central areas of low density or small metropolitan areas or were located in the first ring of suburbs around the central cities.

The sprawl index was negatively and significantly correlated with the all-mode traffic fatality rate, meaning that more compact counties had lower traffic fatality rates (Table 3). For every $1 \%$ increase in the index (e.g., increase in compactness), the traffic fatality rate decreased by $1.49 \%$. The natural logarithms of the sprawl index, average household size, percentage of population of working age, and per capita income, taken together, accounted for $47 \%$ of the variance in the natural logarithm of the traffic fatality rate for all modes.

The sprawl index was also negatively and significantly correlated with the pedestrian fatality rate, after adjustment for exposure. This was true for both measures of exposure and for samples including all counties and only counties with 1 or more pedestrian fatalities. 
TABLE 3-Regression Analysis of Association Between Sprawl Index and Fatality Rates

\begin{tabular}{|c|c|c|c|c|c|}
\hline & \multirow{3}{*}{$\begin{array}{l}\text { Ln of All-Mode Traffic Fatality Rate } \\
\text { (Coefficients and } t \text {-Statistics) }\end{array}$} & \multicolumn{4}{|c|}{ Ln of Pedestrian Fatality Rate (Coefficients and $t$-Statistics) } \\
\hline & & \multicolumn{2}{|c|}{ Adjusted for Walking Share of Commute Trips } & \multicolumn{2}{|c|}{$\begin{array}{l}\text { Adjusted for Walking And } \\
\text { Public Transportation Share of Commute Trips }\end{array}$} \\
\hline & & Counties With Fatalities & All Counties & Counties With Fatalities & All Counties \\
\hline Constant & 15.5 & 12.0 & 14.0 & 29.5 & 31.8 \\
\hline Ln (sprawl index) & $-1.49(-14.7)^{* * *}$ & $-1.47(-6.6)^{* * *}$ & $-2.04(-10.7)^{* * *}$ & $-3.06(-13.6)^{* * *}$ & $-3.56(-18.3)^{* * *}$ \\
\hline Ln (average household size) & $-0.22(-0.8)$ & $2.08(3.3)^{* *}$ & $2.10(3.9)^{* * *}$ & $0.48(0.8)$ & $0.52(0.9)$ \\
\hline Ln (proportion of people of working age) & $1.25(2.3)^{*}$ & $1.27(1.0)$ & $1.76(1.7)$ & $0.97(0.8)$ & $1.12(1.1)$ \\
\hline Ln (per capita income) & $-1.11(-10.0)^{* * *}$ & $-0.80(-3.1)^{* *}$ & $-0.92(-4.4)^{* * *}$ & $-1.61(-6.2)^{* * *}$ & $-1.65(-7.8)^{* * *}$ \\
\hline Adjusted $R^{2}$ & 0.47 & 0.18 & 0.29 & 0.43 & 0.52 \\
\hline Sample size & 448 & 356 & 448 & 356 & 448 \\
\hline
\end{tabular}

${ }^{*} P<0.05$ level; $* * P<0.01$ level; $* * * P<0.001$.

For the 356 counties with pedestrian fatalities, every $1 \%$ increase in the sprawl index (increase in compactness) was associated with a $1.47 \%$ increase in the pedestrian fatality rate, after adjustment for the percentage of trips to work on foot, and a 3.06\% increase in the pedestrian fatality rate, adjusted for the percentage of trips to work on foot or by transit $(P<.001$; Table 3). Sprawl was even more strongly associated with pedestrian fatalities when 1 fatality was added to the count for each county so that all counties could be included in the analysis (Table 3). Thus, regardless of which methodological approach was taken, more compact counties had lower pedestrian fatality rates, after adjustment for exposure and the 3 covariates.

\section{DISCUSSION}

Our study indicates that sprawl is a significant risk factor for traffic fatalities, especially for pedestrians. The recognition of this relationship is key; traffic safety can be added to the other health risks associated with urban sprawl-namely, physical inactivity and air and water pollution. ${ }^{22-24}$

Our study has certain strengths. The data used are of high quality and derive from independent datasets. They represent a very large sample of counties from across the nation, and the findings are significant, robust, and internally consistent. However, our study also has weaknesses. The study design is ecological in nature. It treats each county as a unit of homogeneous density and accessibility and assigns to it a single fatality rate, though large differences within borders are likely. In the future, whenever possible, analysis should involve finer levels of geography, such as census tracts. In certain circumstances, such as the study of behaviors antecedent to injury, analysis may need to extend down to the individual level.

Another limitation is our reduction of the complex phenomenon of urban sprawl to 2 dimensions, population density and street accessibility, as well as our use of only 6 variables to measure sprawl. We did this because county-level archival data were available for the entire nation for very few relevant variables. Future studies should seek or develop county-level, nationwide data for the other key characteristics of sprawl-namely, the rigid separation of homes, shops, and workplaces, as well as the lack of distinct, thriving activity centers, such as strong downtowns or suburban town centers.

We recognize that the fatality data studied are based on the location of a crash, whereas the population density and street accessibility data are based on place of residence, which may be different. To the extent that fatalities occurred during the morning or evening commute, a (reassuring) bias toward the null may exist. In other words, because most commuters who cross county borders live in lower-density bedroom communities and work in higher-density central areas, the traffic fatality rate in urban counties would be inflated relative to the population living there. Using these databases, we could not deter- mine the extent to which such bias, if any, existed. One solution would be to study the relationship at the (multicounty) metropolitan area level, but such a focus would be at the expense of desired precision in the measurement of differences within metropolitan areas.

Finally, the journey-to-work data used to adjust the pedestrian fatality rates may not accurately reflect the overall amount of pedestrian activity occurring within a given county. For example, some people may not walk to work but may prefer this mode for shopping trips, school trips, and errands. Leisure time walking may be prevalent in sprawling places even if there are no shops, workplaces, or other destinations nearby and people are simply walking for exercise. Walk trips may be longer in sprawling places. We cannot determine whether a systematic bias exists among counties, such as might occur if suburban counties have sidewalk or trail systems that provide circulation within subdivisions or lead to nearby recreation sites, schools, and shopping destinations but not to distant workplaces. No travel mode data are currently available for all trip purposes for areas as small as counties.

Vehicle speed may make a large contribution to the difference in fatality rates observed between compact and sprawling counties. ${ }^{25}$ Sprawling areas tend to have wide, long streets that encourage excessive speed. A pedestrian struck by a motor vehicle traveling at 40 mph has an $85 \%$ chance of being killed, compared with a $45 \%$ chance of death at $30 \mathrm{mph}$ and a $5 \%$ chance at $20 \mathrm{mph}^{26}$ 
Thus, developing land in a more compact manner may reduce pedestrian deaths, provided that the street network is designed for lower-speed travel.

Additional studies are needed to confirm these findings and to extend our knowledge in key areas. A replication of results based on 1990 traffic fatality and urban form data would be useful. An exploration of the relationships among vehicle speed, fatality rates, and specific street design features common to urban sprawl (e.g., wide, long streets) would help guide countermeasures. Pedestrian injuries, which are 16 times more common than fatalities, should be studied to determine whether their relationship to sprawl is similar to that of pedestrian fatalities. At present, because no complete and reliable pedestrian injury data are available for small areas, the ability to study injuries requires new datacollection activities. Pedestrian fatalities should be studied for high-risk populations such as the elderly, children, and minorities. Perhaps most important, future research should work toward the development and use of more precise measures of pedestrian exposure to permit a better understanding of the relationship of urban sprawl to traffic risks.

\section{About the Authors}

Reid Ewing is with the Alan M. Voorhees Transportation Center, Edward J. Bloustein School of Planning and Public Policy, Rutgers, The State University of New Jersey, New Brunswick, NJ; Richard A. Schieber is with the Division of Unintentional Injury Prevention, National Center for Injury Prevention and Control, Centers for Disease Control and Prevention, US Public Health Service, Atlanta, Ga; and Charles V. Zegeer is with the University of North Carolina, Chapel Hill, Highway Safety Research Center, Chapel Hill.

Requests for reprints should be sent to Reid Ewing PhD, National Center for Smart Growth, Preimkert Field

House, University of Maryland, College Park, MD 20742

This article was accepted May 5, 2003.

\section{Contributors}

R. Ewing conceived of the study, developed the study design, collected data, and conducted the analysis. R.A Schieber and C.V. Zegeer prepared the manuscript.

\section{Acknowledgments}

Rolf Pendall of Cornell University, John Ottensmann of Indiana University, and William Dolphin of Rutgers University contributed data that became part of the county sprawl index. Randy Elder of the National Center for Injury Prevention and Control helped interpret the statistical tests conducted.

\section{Human Participant Protection}

No protocol approval was needed for this study.

\section{References}

1. Hilton J, Shankar U. 2001 Motor Vehicle Traffic Crashes: Injury and Fatality Estimates, Early Assessment. Washington, DC: US Dept of Transportation, HS 809-439; 2002

2. Federal Highway Administration. National Bicycling and Walking Study: Five Year Status Report by the US Department of Transportation, April 22, 1999. Available at: http://www.fhwa.dot.gov/environment/ bikeped/Study.htm. Accessed December 15, 2002.

3. Surface Transportation Policy Project (STPP) Mean Streets 2002. Available at: www.transact.org/ PDFs/ms2002/MeanStreets2002.pdf. Accessed December 15, 2002.

4. Zegeer C, Stewart R, Huang H, Lagerwey P. Safety effects of marked vs unmarked crosswalks at uncontrolled locations: analysis of pedestrian crashes in 30 cities. Transport Res Rec. 2001;1773:56-68.

5. Zegeer C, Opiels K, Cynecki M. Effects of pedestrian signals and signal timing on pedestrian accidents. Transport Res Rec. 1982;847:62-72.

6. Lucy WH, Rabalais R. Traffic fatalities and homicides by strangers: danger of leaving home in cities, inner suburbs, and outer suburbs. Available at: http:// arch.virginia.edu/exurbia/death-in-exurbia.pdf. Accessed December 15, 2002

7. Ewing R. Is Los Angeles style sprawl desirable? J Am Planning Assoc. 1997;63(1):107-126.

8. Ewing R, Pendall R, Chen D. Measuring sprawl and its impact. Smart Growth America 2002. Available at: http://www.smartgrowthamerica.org/sprawlindex/ MeasuringSprawl.pdf. Accessed December 15, 2002.

9. Ewing R, Schmid T, Killingsworth R, Zlot A, Raudenbush S. Urban form, physical activity and health. Am J Health Promotion. In press.

10. US Bureau of the Census. Census 2000 Summary File 1, Census of Population and Housing. Washington, DC: US Bureau of the Census; 2001.

11. Messenger T, Ewing R. Transit-oriented development in the sunbelt. Transport Res Rec. 1996;1552: 145-152

12. United States Department of Agriculture. 1997 National Resources Inventory [machine-readable data on CD-ROM]. Revised data, Alpha release, March 2001.

13. US Bureau of the Census. UA Census 2000 TIGER/LineR files [machine-readable data files]. Washington, DC: US Dept of Commerce; 2002.

14. US Bureau of the Census. UA Census 2000 TIGER/LineR file technical documentation. Washington, DC: US Bureau of the Census; 2002.

15. Neuman T. Geometric Design: Urban Intersections, The Traffic Safety Toolbox- A Primer on Traffic Safety. Washington, DC: Institute of Transportation Engineers; 1999

16. National Highway Traffic Safety Administration, Fatality Analysis Reporting System (FARS). Washington, DC: US Dept of Transportation. Available at: http://ftp.nhtsa.dot.gov/FARS. Accessed December 15, 2002.

17. Roberts I. Why have child pedestrian death rates fallen? BMJ. 1993;306:1737-1739.
18. Roberts I. What does a decline in child pedestrian injury rates mean? Am J Public Health. 1995;85: 268-269.

19. Roberts I, Keall MD, Frith WJ. Pedestrian exposure and the risk of child pedestrian injury. J Paediatr Child Health. 1994;30:220-223.

20. DiGuiseppi C, Roberts I, Li L, Allen D. Determinants of car travel on daily journeys to school: cross sectional survey of primary school children. BMJ. 1998;316:1426-1428.

21. US Bureau of the Census. Census 2000 Summary File 3 [machine-readable data files]. Washington, DC: US Bureau of the Census; 2002.

22. Frumkin H. Urban sprawl and public health. Public Health Rep. 2002;117:201-217.

23. Jackson RJ, Kochtitzky C. Creating a Healthy Environment: The Impact of the Built Environment on Public Health. Washington, DC: Sprawl Watch Clearinghouse 2001

24. Roper WL, Kraft MK, Killingsworth RE, Mofson P, Starrett B. Health and smart growth: building health, promoting active communities. Funders' Network for Smart Growth and Livable Communities. Available at: http://www.fundersnetwork.org. Accessed December 15,2002

25. Surface Transportation Policy Project (STPP). Aggressive Driving: Where You Live Matters. Available at http://www.transact.org/report.asp. Accessed December 15,2002

26. UK Department of Transportation. Killing Speeds and Saving Lives. London, England: UK Dept of Transportation; 1987 